\title{
Moral Education through Play Therapy
}

\author{
Salwa Mahalle ${ }^{1}$, Gamal Abdul Nasir Zakaria ${ }^{2} \&$ Aliff Nawi $^{2}$ \\ ${ }^{1}$ Language and Literacy Education Academic Group, Sultan Hassanal Bolkiah Institute of Education, Universiti \\ Brunei Darussalam, Brunei Darussalam \\ ${ }^{2}$ Psychological Studies and Human Development Academic Group Sultan Hassanal Bolkiah Institute of Education, \\ Universiti Brunei Darussalam, Brunei Darussalam \\ Correspondence: Gamal Abdul Nasir Zakaria, Language and Literacy Education Academic Group, Sultan \\ Hassanal Bolkiah Institute of Education, Universiti Brunei Darussalam, Brunei Darussalam. E-mail: \\ gamal.zakaria@ubd.edu.bn
}

Received: January 6, 2014 Accepted: February 7, 2014 Online Published: February 25, 2014

doi:10.5539/ies.v7n3p78 URL: http://dx.doi.org/10.5539/ies.v7n3p78

\begin{abstract}
This paper will discuss on how sand therapy (as one type of play therapies) can be applied as an additional technique or approach in counseling. The research questions for this study are to see what are the development, challenges faced by the therapist during the sessions given and how sand therapy can aid to the progress of the client. It is a single case design where one student from one of the secondary schools in Brunei Darussalam was involved as a client. The client was having family problems which led to various problems. Researcher used four methods of collecting data namely; interview, recording, photos and sand tray. Data was analysed through the techniques of sharing, exploring of issues through the organisation of objects in the sand tray. Results showed that the clients can be helped through several sessions of sand therapy in addition to individual counseling sessions.
\end{abstract}

Keywords: play therapy, Brunei Darussalam, secondary schools, moral education

\section{Introduction}

Sand therapy is one type of play therapy and it was introduced by Dora Marie Kalff based on the Personality Theory by Carl Jung. Kalff believed that the interpretation of stories slowly can provide space for client to experience intense transformation in psyche. Based on Jungian's concept, psyche has the tendency to work towards wholeness and sand therapy is able to activate this process in the inner self of the client despite the fact that the therapist being quiet. According to Boik and Goodwin (2000), Kalff viewed the sandtray as a location for clients to express their interpersonal world, in symbolic form. Kalff believed that when clients are given the chance to construct concrete images of themselves in a safe environment, they would reconcile disconnected aspects of their inner and outer selves and achieve a new wholeness marked by balance, congruence and integration of the conscious and unconscious.

Sand therapy is an approach wherby images are created in a tray filled with wet or dry sand as the therapist sits quietly nearby. Sometimes the client talks about his/her life issues or problems and the therapist responds; other times both remain silent. Over the course of therapy, a process of development and healing may be seen and sometimes up to a certain level, understanding of the issues happened. In sand therapy, imagination of the client is needed and the therapist would wait for the wisdom of the client's psyche to unfold in the series of sand pictures. The image seems to beg for relationship, to be received and appreciated by someone. Hence, the therapist serves as a midwife for these images by receiving them just as they are, allowing them their own pace for emerging into the outer world.

Meanwhile, in Japan, sand therapy is also used as one of the tools to counsel children and adults. It is known as "Hakaniwa" or "box garden", where the clients work with sand and a variety of figurines and objects within the dimensions of a large, shallow sandtray to reflect their personal worlds. Sandtray approach as mentioned by Enns and Kasai (2003), can convey significant artistic and spiritual values and are often used to depict the beauty of the larger world within a symbolic microcosm.

During the session, there are times where both parties (therapist and client) are in silence. It seems that silent, respectful acceptance of the images created during the sand therapy process allows the client to feel increasingly 
safe and free. As this happens the images seem to come less from the ego and personal unconscious, and more from the deeper levels of the human psyche, or the collective unconscious. If, as Jung believed, the human psyche has the ability to regulate its own path towards wholeness, healing comes from this deep level of the psyche rather from outside.

The essentials of sand therapy are a specially proportioned sandtray, a source of water, shelves of miniatures variety; people, animals, buildings, bridges, vehicles, furniture, rocks and the list goes on and an emphatic therapist who provides the freedom and the protection that encourages children (or adults) to experience their inner, often unrealised, selves in a safe and non-judgemental space. The therapist as a witness is an essential part of the method, but this therapist is in the mode of "appreciating", not "judging", what the sandplayer does. It is necessary that the therapist follow the play and stays in tune with it, but not intrude. It is also advisable to alternate individual counseling with sand therapy. When the therapist understands or has a picture of what the client's issues are, more exploration can be done through individual sessions. In the context of Brunei Darussalam, a therapist can take this opportunity to inject some religious and moral values on the client so that the client is aware that in Islam there are some things which are allowed and also not allowed. More details will be given in relation to the case study presented in this paper.

Today, sand therapy is used as a treatment to both children and adult in various types of clinical issues such as trauma, personal development and so forth. Sand therapy can be divided into two namely: open space sand play and sand tray (in a specialised room).

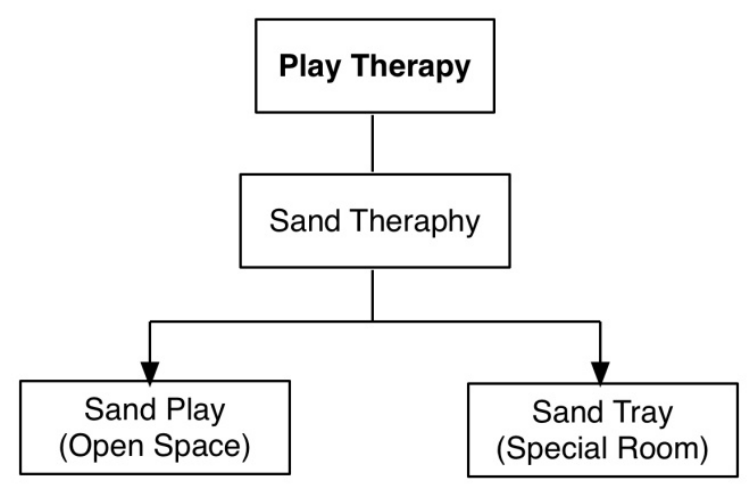

Figure 1. Types of sand therapy

An example of sand play in an open space is at the beach, recreational parks and so forth. Sand is a therapeutic material for instance; it can be a treatment for someone who is having skin disease. For some of the Malay traditions, sand is believed to have the right heat or temperature which can be used in the treatment for women who have just given births. 


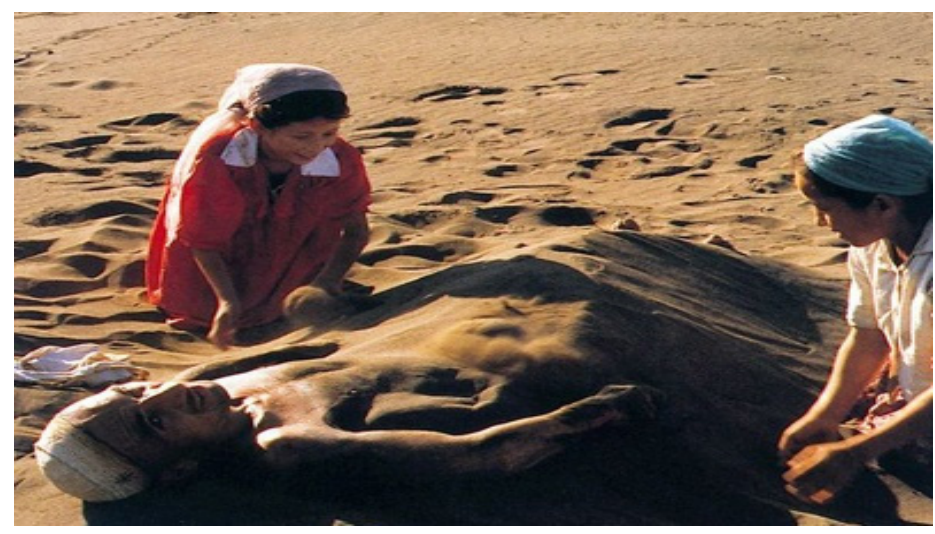

Figure 2. An example of sand play at the beach

Meanwhile, sand play using sand tray can be done in a special room as one of the processes of psychotherapies (see Figure 3) and this room can be called as the therapy room.

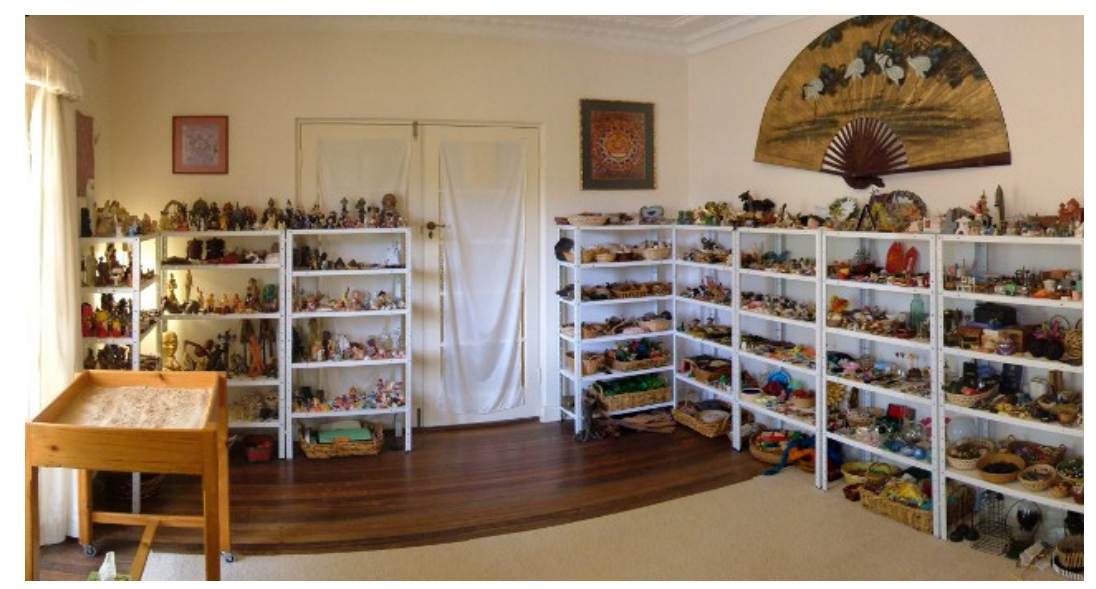

Figure 3. Special room for sand theraphy

Sand tray enable to give space for clients to give meanings to the symbols they used and the arrangements of those symbols or objects whereby the interactions and relationships in his world can be portrayed. In the sand therapy sessions, clients are able to move and create and at the same time these movements can aid in the individual's development through the combinations of elements of emotions, cognitive, social and physical.

Many therapists build their personal collections by gathering potentially meaningful objects from the natural environment and purchasing small figures that represent people, animals, plants, machines and utensils or structures used in daily living. Therapists would seek to build collections that will allow clients to express their worlds as completely and imaginatively as possible.

Usage of sand therapy suits clients who are:

- Shy

- Quiet and not talkative

- Not the acquaintance of counsellor

- Having difficulties in sharing and letting out their feelings

- Autistic

Clients will have the chance to choose and arrange the symbols and miniatures according to their likings and placed those objects in a sandtray to "picture" what are in their minds in a 3-D way. Clients are free to play and be creative. 
The therapist usually sits quietly and watches, sometimes drawing a sketch or jotting down some notes to maintain records of the clients' creation (Weinrib, 1983). The therapist is attentive to: a) how the client creates the sandtray (such as the mood and body posture of the client) and; b) the content of the tray (for instance shapes created by the client, spatial relationships and so forth).

\subsection{Objectives of Sand Therapy}

Among the objectives in a sand therapy session are to:

- Help in the individual's development in terms of interactions with others.

- Help in the psychomotor's development of a child.

- Encourage clients to let out the emotions of the individual's inner self.

- Encourage interaction and communication (verbal and non-verbal).

- Integrate physical, emotional and social experiences in promoting individual's self confidence.

\subsection{Target and Suitability of Sand Therapy}

Sand therapy is suitable for clients of all age groups, that is, from child to adults. Besides that, this therapy can also be used for individual counseling, pairing and group counseling.

\subsection{Setting}

Before the session starts, the counselor or therapist must prepare all the basic needs and the materials which are going to be used in that therapy session. These materials must be arranged in a systematic way so that clients will not have any problems in searching and looking for them. The room must be conducive, comfortable and physically secure in terms of cleanliness, lighting, colour of the room and not noisy. Not only that, the room must be psychologically safe in terms of trusting each other, teamwork, cooperation and respectful between the counselor and client.

\subsection{Process Involved}

To handle a sand therapy session, there are few processes which have to be taken into account, namely:

\section{Step 1:}

- Self introduction from the counselor and client

- $\quad$ Ethics such as practicing confidentiality

- Requirements of the sessions such as puntuality, committment and so forth

- Briefing on the processes involved such as structuring and so forth

\section{Step 2:}

- Therapist and client will sit/stand next to a sand tray and the miniatures which are going to be used during the therapy session.

\section{Step 3:}

- Client is free to choose and arrange these miniatures or objects in the sand tray provided according to his creativity. To enable client to do this, therapist must allocate certain duration and leave the client alone. During this process, the therapist will be in the same room but a distance away from the client. Normally, therapist will not talk much during this process and act as a "dumb-witness" (depending on the age group and types of client). As mentioned by Kalff (1980), the primary roles of the therapist are to provide a "free and protected space", develop a "wordless rapport" with the client and bear witness to the sandplay's act of creation.

\section{Step 4:}

- When this step is done, client will explain to the therapist the meanings and his relationships to those symbols used. Here, questions and answer sessions will happen in order for the therapist to explore more on the story created and enable client to share what had happened. In this stage, therapist will use open and close ended questions and simultaneously observe the emotions expressed by the clients. As the therapist gets more information of the issues client is having, this is also the opportunity for the therapist to instill moral values to the clients depending on the nature of the problems discussed.

\section{Step 5:}

- Before ending the sessions, therapist will set a date for the next session. Number of sessions required depends on the types of problems faced by the client and how the client progress in every sessions. 
- Usually, individual counseling sessions will be given so that client will be able to talk more about his problems and therapist will be able to explore more.

\section{Significance of the Study}

The main socialization agent for a child is his/her parents. Parents have strong influence over the child's behavior, attitude and personality. Parents too may influence the socialization pattern of their child through various ways such as direct learning, giving information, reinforcing good behavior, just to name a few. Apparently, parents can be the role model for the child's attitudes, beliefs and behavior.

For that matter, the case study presented in this paper is crucial in the development of emotional and intellectual of students (clients) whereby sand therapy can also be used for secondary school students. Through sand therapy client is given the opportunity to pour out their emotions which will then be followed by individual counseling. Research done by Bratton et al. (2005) showed that the effects of play therapy interventions are more positive for humanistic than for non humanistic treatments. Therefore, they concluded that play therapy appeared equally effective across age, gender and presenting issue.

\section{Limitation of the Study}

One of the limitations faced by the therapist when conducting this study was time factor. Therapist had the chance to do two sessions of sand therapy and few sessions of individual counseling, due to the fact that client had examination to prepare for. As mentioned earlier, this study is a single case study, hence in this paper researcher will only describe the sessions done on a client of Year 8 who was studying in one of the secondary schools in Brunei Darussalam. The client was in the commotion of being stressed and pressured due to the family problems she was facing.

\section{Objective of the Study}

This study focuses on three objectives namely to:

a) Investigate on how the sand therapy helped in the process of counseling;

b) State the development and progress of the client during the treatment;

c) Identify the challenges faced by the counselor when conducting individual counseling sessions and sand therapy on the client.

\section{Research Questions}

The research questions are:

a) How can sand therapy help in the process of counseling?

b) What are the developments or progress of the client during the treatment?

c) What are the challenges faced by the counselor when conducting individual counseling sessions and doing the sand therapy on the client?

\section{Literature Review}

Sand therapy has recently been practiced and introduced in Brunei Darussalam as one of the approaches in conducting counseling sessions. Sand therapy can be used in helping children and adults as the clients. Through sand therapy, it can help in emerging the intense transformation experience from both parties, the therapist and the client (Pattis, 2002; Reece, 2004) besides giving chances for the individuals to explore more on the matters pertaining to deep emotional issues.

Traditionally, family therapists used verbal therapy as the primary mode of communication with older children who attend family therapy sessions. Infact, family therapy sessions can be greatly enhanced by using play therapy to help children and families communicate through symbols, metaphors and stories. Family therapists can employ techniques such as puppet play, mutual story-telling and family art to establish new patterns of dynamic interaction, create an atmosphere of enjoyment, and undertake innovative methods of establishing emotional relatedness, improving family communication and helping families learn more effective problem solving skills. Having said that, sand therapy approach is not an acception.

In Europe, Japan and the United States, sand therapy is acknowledged as one of the effective therapeutic tools in handling cases like traumas and depression. Touching gestures and non-verbal experience can also help in promoting the awareness towards very personal emotional problems in a quiet and therapeutic condition. This was clearly mentioned in the study done by Herman (1997) where he found that his client was able to 'bring up' sensitive issues through sand therapy. The arrangement of miniatures and symbols can help in reflecting the 
inner world of client and raise the spontaneous metaphora and through narration can help the therapist understand the story of trauma client was facing. The essence of sand therapy is non-verbal and symbolic. Sand therapy may open person to re-experience pre-verbal and non-verbal states.

According to Gill (2006), sand therapy is one type of intervention whereby a client is given a space to reconstruct a story of the issue he is facing. This statement is based on his study done on his client named Justin where Justin was involved in a serious car accident where two of his best friends were killed. Briefly, Justin had few sessions with Gill. Justin chose miniatures of people which he named after his best friends who survived and were killed in that tragedy. He further chose a helicopter and bravely acted a scene where the helicopter was flying, fighting and later on crashed. He was the director of the story and through sand therapy, he played the main character, editor and reconstruct the story in order to heal himself.

In counseling, sand therapy can be applied. According to Vygotsky (1967), through playing one can develop literally and intellectually. The brain structure will be shaped through the use of symbols. Playing too can give freedom to children in order for them to pour out their problems. Therefore, in this way, children will be able to control the situation and able to process their thinking skills to a higher level. In the Islamic context, this is the role of the therapist to help the client to accept (redha) on what had happened to him. According to Daud and Bond (2013), some Muslims are suspicions of "secular" psychotherapy, because they do not want to abandon cultural traditions of kinship or spiritual-religious models of treating psychological distress and behavioral deviance. The counselor should attempt to work within the moral and cultural framework of the client.

Therapists should help the client to identify the specific origin of beliefs about authority and disciplinary practices, then compare their benefits and harm. Letting out your emotions is one way of reducing depression because emotions will eventually control you if you let them build up. Allah will never leave his servant helpless with a sincere intention of wanting to change and live a faithful and prosperous life. We need to put our faith in Allah and trust that he will protect us from anything and everything. For instance, mental or emotional distress may be expressed somatically, as the locus of emotion, rationality and the soul is located in the physical heart in traditional Islamic psychology. Mental distress is generally expressed as moral transgression or the result of Divine will. Thus, Muslims often prefer religious interventions or methods for healing. These include fasting (sawm), repentance (taubah) and regular recitation (zikr) of the Qur'an to regain intimacy with Allah.

\section{Research Design}

Single-case research has played an important role in developing and evaluating interventions that are designed to alter a particular facet of human functioning. This research is of the form of case study which uses qualitative data and is most suitable to be used in a study which involves only an individual, one group, one unit and so forth (Burn, 1995). The classic single-case research design is typically identified as an A-B-A design. The logic of the A-B-A design is straightforward. A is when the severity of the problem is quantified in a baseline period before treatment is introduced. $\mathrm{B}$ is done when the treatment is then introduced with continuing measurement of the problem. Last but not least, A is when treatment stops but the measurement of the problem continues for a period of time. In counseling, it is expected that any interventions being provided by counselors is expected to have a long lasting effect.

In this study, data was collected through interviews, pictures and reports of every counseling session done on the client involved.

\section{Results and Discussion}

This paper will explain on how a client from a secondary school in Brunei Darussalam was initially having stress and with the treatment of sand therapy and individual counseling sessions, the client had shown some improvement. She can then be able to control her emotion and be more focus on her study.

\subsection{Case Note: Client's Background}

Client is 14 years of age, female, having problems in coping her stress and not able to focus on her study. Her father had retired and the mother was working as a cook. Client is the youngest child in the family (having four other siblings). Part of the reason on why client was having this problem was due to the fact that her parents were constantly quarelling even to the extent of planning to be divorced. Counseling sessions and sand therapy treatment were done alternately.

During the first session of individual counseling, counselor did some structuring with the client so that good rapport would be established between the counselor and client. At first, client seemed very sad and reluctant to share her problem. In the second meeting with the client, counselor used sand therapy and explained what should be done in that session. Client was asked to pick any miniatures as to symbolize the characters in her family. 
Later, the miniatures were then arranged in the tray filled with sand at the same time explaining to the counselor the meaning of the arrangement. In this stage, counselor posed some questions so that counselor was able to understand and grasp all the feelings involved (See Figure 4).

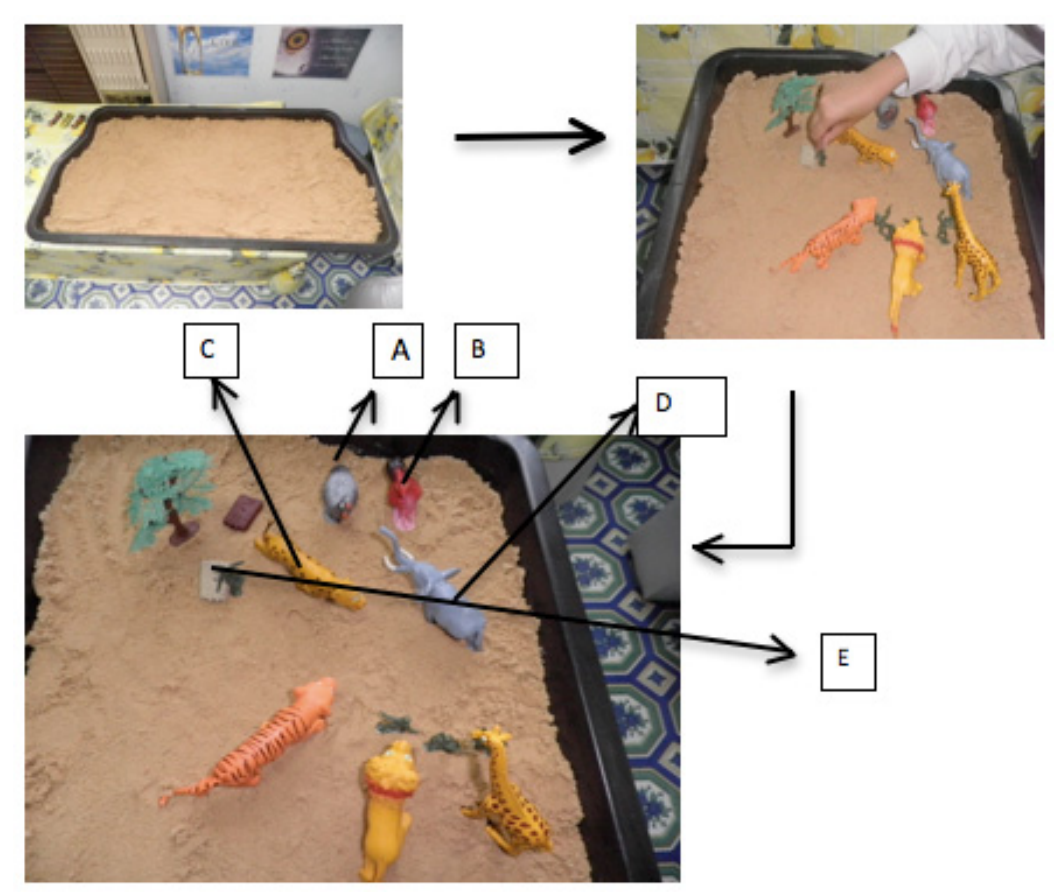

Figure 4. Results of sand therapy (first session)

From the diagram above, client explained to the counselor what each miniature represents, namely (Table 1):

Table 1. Symbols represent each miniature

\begin{tabular}{lc}
\hline A: (Duck) & Uncle \\
B: (Hen) & Aunty \\
C: (Tiger) & Father \\
D: (Elephant) & Mother \\
E: (Small animal) & Client \\
\hline
\end{tabular}

From the arrangement, it shows the scene that had happened when the parents were having their fight. It happened in front of the client and her other siblings. The fight got worse where the father beat the mother and this was when the client ran out of the house and called the uncle and aunt for help, who happened to live nearby. The following session was individual counseling where more exploration was done by the counselor. Counselor reminded client what the roles of children are towards parents as outlined in the teachings of Islam aside from sharing what other techniques can be applied as to reduce the feeling of stress and pressured.

Having done few sessions, some changes in the arrangement were observed by the counselor (See Figure 4). 


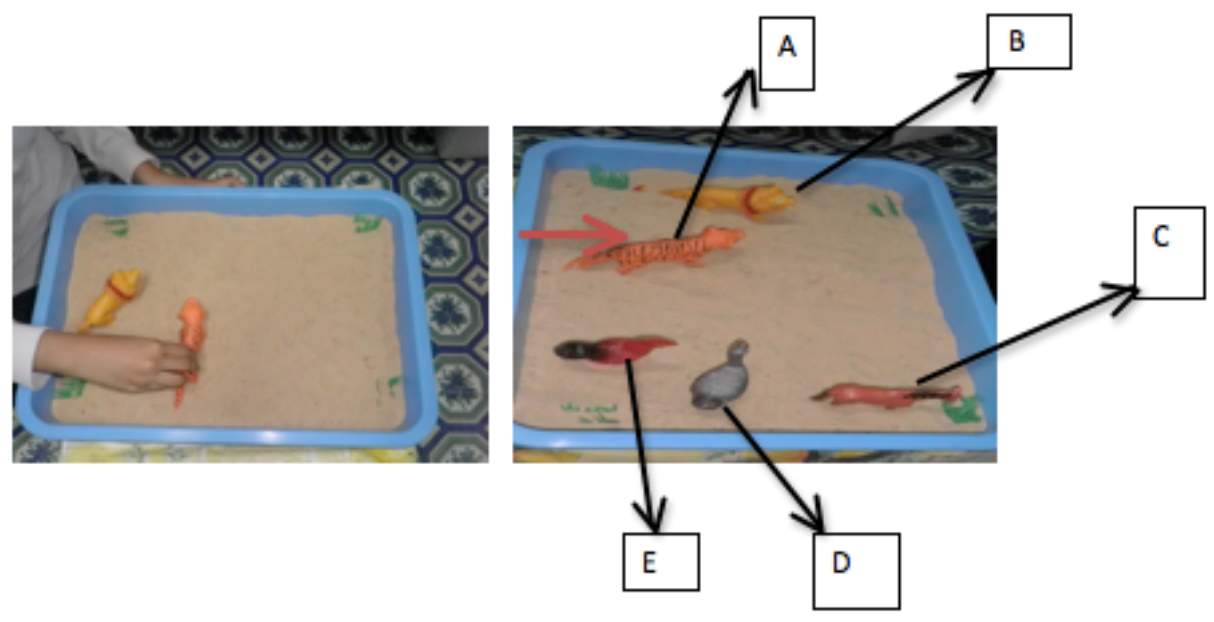

Figure 5. Results of sand therapy (second session)

From above (Figure 5), symbols represent:

Table 2. Symbols represent each miniature

\begin{tabular}{lc}
\hline A: (Tiger) & Father \\
B: (Lion) & Mother \\
C: (Horse) & Client \\
D: (Duck) & Sister \\
E: (Hen) & Youngest Brother of the client \\
\hline
\end{tabular}

To answer the second research question of this study, that is to investigate the developments or progress observed on the clients, Figure 4 explains it pictorially where the client explained that the father and mother were watching television in the room. Meanwhile, client with the other siblings were studying in a different room. According to client, the parents did not fight anymore and the idea of getting divorced subsided. Eventhough, counselor could only manage to have two sessions of sand therapy and few sessions of individual counseling, some positive changes on the client were observed such as in the arrangement of the miniatures and client began to be able to focus on her study. These results supported a study by Reece (2004) whereby through sand therapy, client was given the opportunity to do self-exploration and deep feelings which were hidden were able to be brought up to the surface. Furthermore, the results of this study are in agreement to the research done by Bratton et al. (2005) where in that research, they studied the effects of play therapy interventions and results showed a positive effect for humanistic treatments. Hence, this explains why the positive changes observed on the client.

From the first and second sessions of sand therapy in this research, it can be observed that the client was opened to becoming acquainted with her feelings and life patterns and further learnt to access inner capacities that facilitate healing. Similar to the research done by Herman (1997), on his trauma client, whereby he too found that through the sand therapy he had with his client, the symbols used were able to help in reflecting the inner world of the client. In other words, the sand play process often facilitates the therapeutic alliance and compared to many verbal therapies, may decrease the time needed to unlock non conscious or blocked themes and issues. Therefore, these explanations basically answered the first research question pertaing on how the sand therapy aids both the clients and counselor during the treatments done.

In this study, the client began to accept the reality and managed to make an effort to focus on her studies. Client needs to make internal adjustments to reality by modifying her personal goals, expectations and attributions. According to Bankart (1997), this type of acceptance of fate or reality will allow one to achieve harmony with one's circumstances and positive coping.

From a Jungian conceptual framework, sandtherapy allows clients to use a vocabulary of symbols to express their imagination, emotion and thinking. Through the act of shaping sand and placing miniatures in a scene, individuals 
communicate through personally relevant myths and feelings. From a person-centred perspective, sand therapy may be viewed as a method for increasing the range and depth of the clients' emotional experience and present awareness. From an Adlerian perspective, creations of sand and miniatures objects can be viewed as manifestations of a client's lifestyle and client can also use sand expression to reconstruct and reorient his or her lifestule statements.

In terms of the third research question, from the case notes done, it was observed that at the early session of individual counseling, client was at first lost and confused and at times being silent. It was a challenge for the counselor in exploring more issues faced by the client. When given chance to do the sand therapy, initially the client took quite some time and was in deep thoughts. Finally she managed to arrange the miniatures reflecting her emotional sides. As time went by, with the next individual counseling sessions and the second session of sand therapy, the client seemed more relaxed and comfortable. Another challenge faced by the counselor was the time factor. Counselor managed to conduct only two sessions of sand therapy. Nevertheless, in the second sessions, positive developments were seen and client was happy because her parents had decided not to be divorced.

\section{Conclusions}

Sand therapy is a powerful and fascinating therapeutic technique, provides optimal effectiveness in working with injured children and adults. Children who are abused often find it difficult to verbalise their thoughts and feelings regarding terrifying, confusing and upsetting events. Art, sand therapy and other expressive techniques have long been used to allow individuals to bring forward their unconscious fears, world views and images of healing.

Sand therapy comes from creating the sand picture itself, as a form of active imagination, not in focusing on cognitive processing or on the completed production. The counselor or therapist is a witness who primarily reverberates emphatically to the person playing in the sand. The variety of figures and the sensory experience of sand and water also stimulate the unconscious.

In Brunei Darussalam, clients such as teenagers may have difficulty in expressing their feelings for fear of displeasing others (Gamal, Tajudeen, \& Salwa, 2014). He or she may be fearful of inadvertently offending the counselor rather than devoting energy to self exploration. The very act of sitting face to face with a counselor and experiencing direct eye contact may trigger discomfort. In these situations, sand therapy may represent an ideal form of psycho-therapy because the therapist or counselor observes unobstrusively, the client may be less likely to spend energy 'reading' the counselor's reactions. Furthermore, the client does not need a rich vocabulary of emotional words to describe his or her experience but can create images and emotional scenes that explain the client's concerns.

In Islam, it is mentioned in Surah Al-Israa': Verse 82:

"And we reveal of the Quran that which is a healing and a mercy to the believers, and it adds only to the perdition of the unjust."

In short, form the Islamic perspectives, it has been clearly mentioned that there are solutions and ways of healings all issues faced by men.

\section{References}

Adz-Dzaky, H. B. (2001). Psikoterapi \& konselingislam. Yogyakarta: Fajar Pustaka Baru.

Boik, B. L., \& Goodwin, E. A. (2000). Sandplay therapy: A step by step manual for psychotherapists and diverse orientations. New York: Norton.

Bratton, S., Ray, T., \& Jones, L. (2005). The efficacy of play therapy with children: A meta-analytic review of treatment outcomes. Professional psychology research \& practice, 36(4), 376-390. http://dx.doi.org/10.1037/0735-7028.36.4.376

Burns, R. (1995). Introduction to research methods. Melbourne: Longman.

Corey. G. (1994). Theory and practice of group counseling. California: Books/Cole Publishing Co.

Daud, N. A. M., \& Bond, T. (2013). Cultural values and attitude towards guidance and counseling services in one secondary school in Malaysia: The role of a school cultural system. British journal of guidance and counseling, 41(5), 544-558. $\quad$ Retrieved from http://www.tandfonline.com/doi/abs/10.1080/03069885.2013.773957\#.Uu-1YXeSxlw

Enns, Z. C., \& Kasai, M. (2003). Hakoniwe: Japanese sandplay therapy. The counseling psychologist, 31(1), 93-112. http://dx.doi.org/10.1177/0011000002239403 
Gamal, Z., Tajudeed, \& Salwa, M. (2014). Re-engineering values into the youth education system: A needs analysis study in Brunei Darussalam. International Educational Studies, 7(14).

Gill, E. (2006). Helping abused and traumatised children: Integrated directive and non-directive approaches. New York: Guildford Press.

Herman, J. (1997). Trauma and recovery. New York: Basic books.

Homeyer, L. E., \& Sweeney, D. S. (1998). Sandtray: A practical manual. Canyon Lake, TX: Lindan Press.

Kalff, D. M. (2003). Sandplay: A psychotherapeutic approach to psyche. California: Temenos Press.

Najati, M. U. (2005). Hadits dan ilmu jiwa. Bandung: Pustaka.

Pattis. E. (2002). What can a Jungian analyst learn from sandplay? Journal of sandplay therapy, 11, 29-41. Retrieved from http://www.sandplay.org/abstracts/j-11-1-pattis_eva.htm

Reece, S. T. (2004). The crucial moment in sandplay relationship: The therapist's emotive experiences. Journal of sandplay therapy, 13, 131-146. http://www.sandplay.org/abstracts/j-13-1-reece_sachiko_taki.htm

Spodek, B. (1983). Handbook of research in early childhood education. New York: The Free Press.

Turner, B. A. (2005). The handbook of sandplay therapy. Cloverdale, CA: Temenos Press.

Weinrib, E. L. (1983). The image of the self: The sand play therapy process. Cloverdale, CA: Temenos Press.

\section{Copyrights}

Copyright for this article is retained by the author(s), with first publication rights granted to the journal.

This is an open-access article distributed under the terms and conditions of the Creative Commons Attribution license (http://creativecommons.org/licenses/by/3.0/). 